\title{
DETERMINAÇÃO DA CURVA DE FLUXO DO ALUMÍNIO EM DIFERENTES CAMINHOS DE DEFORMAÇÃO ${ }^{1}$
}

\author{
Pedro Henrique Moreira Magalhães ${ }^{2}$ \\ Tercio Assunção Pedrosa ${ }^{3}$ \\ Roberto Braga Figueiredo ${ }^{4}$ \\ Maria Teresa Paulino Aguilar ${ }^{4}$ \\ Paulo Roberto Cetlin ${ }^{5}$
}

\begin{abstract}
Resumo
As curvas de fluxo dos materiais metálicos dependem de diversos parâmetros. Os mais estudados são temperatura, taxa de deformação e encruamento. Além desses parâmetros, o caminho de deformação (ordem e sequência de deformação) também influencia a curva de fluxo. O estudo da influência do caminho de deformação é complexo devido à dificuldade de se isolar os planos de cisalhamento entre passes de deformação. Neste trabalho utilizam-se duas técnicas para isolar o plano de cisalhamento: o ECAP, "Equal Channel Angular Pressing", e o ensaio de cisalhamento. As curvas de fluxo foram determinadas para ensaios monotônicos e em ensaios com mudança na direção de cisalhamento em alumínio puro. Os resultados indicam que o caminho de deformação influencia a curva de fluxo.

Palavras-chave: Caminho de deformação; Alumínio; Equal channel angular pressing.

\section{DETERMINING FLOW CURVES OF ALUMINUM THROUGH DIFFERENT STRAIN PATHS}

\begin{abstract}
Multiple parameters affect flow curves of metallic materials. The most studied parameters are temperature, strain-rate and strain-hardening. Another parameter that affects the flow curves, which is far less studied than the former, is the strainpath. The study of the effect of strain-path on the flow curves is not easy, due to the difficulty to isolate and control the deformation shear plane in sequencial deformation steps. In the present paper two techniques are used to isolate and control the shear plane: Equal-Channel Angular Pressing and shear tests. Flow curves were determined for monotonic loading and in situations where the shear sense and direction are changed in sequential steps. The results show significant effects of the strain-path.
\end{abstract}

Key words: Strain-path; Aluminum; Equal-channel angular pressing.

1 Contribuição técnica ao $68^{\circ}$ Congresso Anual da ABM - Internacional, 30 de julho a 2 de agosto de 2013, Belo Horizonte, MG, Brasil

2 Graduando. Departamento de Engenharia Metalúrgica e de Materiais, Universidade Federal de Minas Gerais (UFMG), Belo Horizonte, MG, Brasil

3 Pesquisador. Centro de Desenvolvimento de Tecnologia Nuclear, Belo Horizonte, MG, Brasil.

4 Professor. Departamento de Engenharia de Materiais e Construção Civil, UFMG, Belo Horizonte, MG, Brasil.

5 Professor. Departamento de Engenharia Mecânica, UFMG, Belo Horizonte, MG, Brasil. 


\section{INTRODUÇÃO}

As curvas de fluxo de metais descrevem a relação entre a tensão aplicada no corpo de prova e a deformação resultante. Entre os fatores que influem na curva de fluxo destacam-se o encruamento, a temperatura e a taxa de deformação. O encruamento é o fenômeno de endurecimento de materiais metálicos por deformação plástica a frio,no qual a tensão de escoamento aumenta com o aumento da deformação plástica e a ductilidade diminui. Em geral, com o aumento da temperatura de ensaio as tensões de escoamento diminuem e a ductilidade aumenta. A taxa de deformação pode ser entendida como a variação da deformação com o tempo. Um aumento da taxa de deformação normalmente aumenta a resistência mecânica do material elevando os valores de tensão na curva de fluxo. ${ }^{(1)}$.

Outro fator que influi na curva de fluxo é o caminho da deformação ou a relação entre as direções e sentido dos passos de cisalhamento impostos. Modificações no caminho de deformação podem levar a amaciamento do material, endurecimento ou transientes na curva de fluxo. Existem poucos estudos sobre o efeito do caminho de deformação devido à dificuldade de se isolar esse parâmetro. $\mathrm{O}$ estudo do efeito do caminho de deformação na curva de fluxo dos materiais deve ser conduzido através de processos ou ensaios em que a direção e o sentido da deformação são conhecidos. Um processo em que é possível controlar a direção e o sentido do cisalhamento é o ECAP (Equal Channel Angular Pressing). Neste processo um corpo de prova de formato prismático é submetido a prensagem através de uma matriz constituída por dois canais de seção transversal iguais que se interceptam formando um ângulo. ${ }^{(2)}$ A Figura 1 ilustra o processo de ECAP. A passagem do corpo de prova por essa matriz leva à deformação por cisalhamento na região de interseção entre os canais. Portanto, em matrizes em que o ângulo entre os canais é $90^{\circ}$, o plano de cisalhamento forma um ângulo de $45^{\circ}$ com a direção axial do corpo de prova.

O cisalhamento imposto durante o ECAP pode levar ao aparecimento de anisotropia no comportamento mecânico dos materiais. Essa anisotropia é causada pelas diferentes relações de caminho de deformação dependendo da direção do ensaio posterior ao ECAP. Ensaios de compressão em cobre, processado por ECAP, em direções ortogonais (direções $x, y$ e $z$ da Figura 1 ) revelaram significativas diferenças nas curvas de fluxo e estas diferenças foram atribuídas ao efeito do caminho de deformação. ${ }^{(3)}$ Entretanto, um estudo mais detalhado do efeito do caminho de deformação não pode ser determinado em ensaios de compressão após o ECAP pois não é possível isolar a direção do cisalhamento neste ensaio. Por outro lado, isto poderia ser obtidoatravés de um ensaio de cisalhamento em chapas. Dessa forma, é possível avaliar a influência do caminho de deformação utilizando-se a sequência ECAP e ensaio de cisalhamento. $O$ presente artigo apresenta resultados desta sequência de deformação em alumínio comercialmente puro.

\section{MATERIAIS E MÉTODOS}

O material utilizado no trabalho foi o alumínio comercialmente puro. A composição química com os teores das principais impurezas encontradas no material é apresentada na Tabela 1. O material foi recebido no formato de um lingote fundido. Este material foi deformado a frio e recozido a $450^{\circ} \mathrm{C}$ em forno tubular com atmosfera de argônio. 
Tabela 1. Composição química do alumínio em \%, determinada por espectrometria ótica

\begin{tabular}{|c|c|c|c|c|c|c|}
\hline $\mathrm{Al}$ & $\mathrm{Fe}$ & $\mathrm{Si}$ & $\mathrm{Li}$ & $\mathrm{Ga}$ & $\mathrm{Zn}$ & $\mathrm{V}$ \\
\hline 99,700 & 0,110 & 0,055 & 0,050 & 0,012 & 0,008 & 0,006 \\
\hline
\end{tabular}

Barras prismáticas com seção transversal quadrada de $16 \times 16 \mathrm{~mm}^{2}$ e comprimento de $100 \mathrm{~mm}$ foram usinadas a partir do material recozido. Algumas delas foram processadas por um passe de ECAP à temperatura ambiente, utilizando uma matriz com ângulo entre canais de $90^{\circ}$ e sem curvatura externa. Esta geometria da matriz impõe uma deformação cisalhante de $2,0{ }^{(4)} \mathrm{O}$ plano de cisalhamento neste caso está inclinado a $45^{\circ}$ em relação aos planos xz e yz da Figura 1.

Chapas com $16 \mathrm{~mm}$ de largura, $100 \mathrm{~mm}$ de comprimento e $1 \mathrm{~mm}$ de espessura foram cortadas por eletroerosão a partir do material recozido e do material processado por ECAP. As chapas oriundas do material processado por ECAP foram cortadas paralelas ao plano que contém os canais da matriz de ECAP (plano xy na Figura 1). Após o corte, as chapas recozidas e processadas por ECAP foram submetidas a ensaios de cisalhamento utilizando-se um dispositivo constituído por duas garras iguais que deslizam em guias que permitem movimento em apenas uma direção (Figura 2). A direção do movimento das garras foi a direção x da Figura 2. Dessa forma, os corpos de prova, no formato de chapas, sofrem cisalhamento no plano xz. A distância entre as garras, na região de cisalhamento é de $3 \mathrm{~mm}$. Portanto, a deformação cisalhante é calculada como o deslocamento das garras na direção $x$ dividido por $3 \mathrm{~mm}$. A tensão cisalhante observada durante o ensaio foi calculada dividindo-se a carga pela área da seção de cada corpo de prova no plano $\mathrm{xz}$.

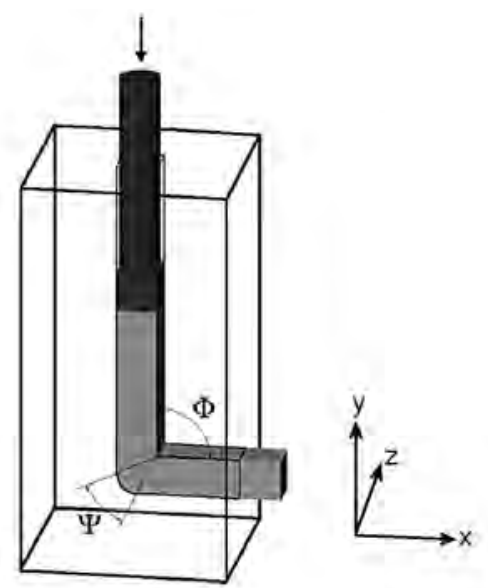

Figura 1. llustração do processo de ECAP.

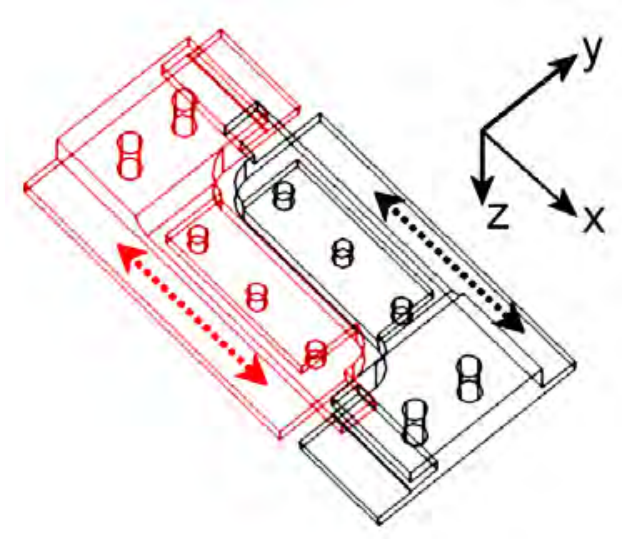


Figura 2. Ilustração do dispositivo utilizado em teste de cisalhamento.

Para a realização dos ensaios de cisalhamento utilizou-se uma máquina de ensaios universal Instron. Os ensaios foram realizados com taxa de deslocamento do cabeçote constante. Alguns ensaios foram interrompidos e recarregados no mesmo sentido anterior ou em sentido oposto ao anterior para observação de eventuais alterações na curva de fluxo.

\section{RESULTADOS}

A Figura 3 mostra as curvas de tensão cisalhante em função da deformação cisalhante para o material recozido carregado em cisalhamento com duas diferentes taxas de deformação. Observa-se que o material apresenta encruamento considerável nessa condição. Em ambas taxas de deformação a tensão de escoamento de $\sim 20 \mathrm{MPa}$ aumenta para uma tensão de fluxo de $\sim 40 \mathrm{MPa}$ após deformação de $\sim 0.5$. Observa-se também que a tensão de fluxo aumenta com o aumento da taxa de deformação.

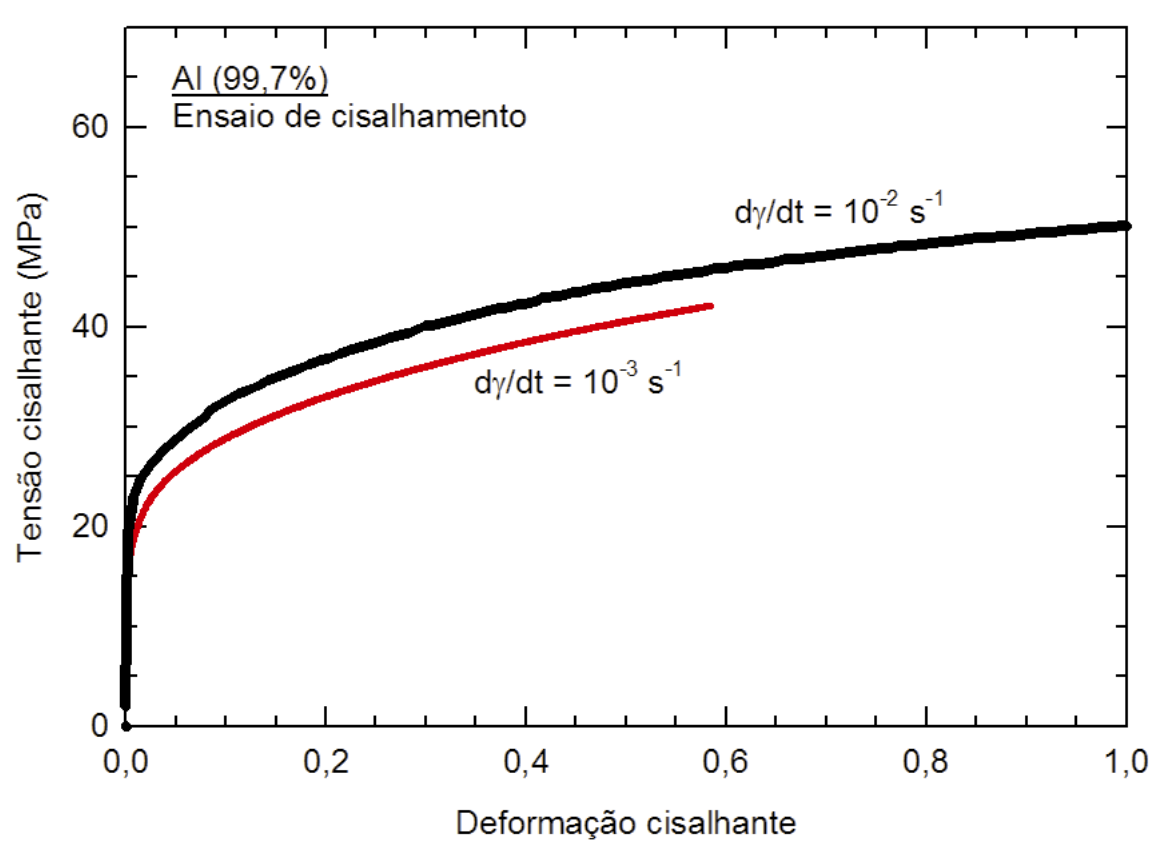

Figura 3. Curva de fluxo do alumínio recozido deformado por cisalhamento em diferentes taxas de deformação.

A Figura 4 mostra curvas de fluxo do alumínio recozido deformado por cisalhamento seguindo-se diferentes mudanças de sentido de deformação. A deformação do corpo de prova foi interrompida após uma deformação de $\sim 0,6$ e reiniciada na mesma direção seguindo-se deformação até um nível de $\sim 1,25$. Neste instante 0 ensaio foi interrompido e a direção do ensaio foi invertida. A deformação do material prosseguiu até atingir um nível de tensão semelhante ao que foi observado na interrupção anterior. Neste ponto (deformação de $-1,8$ ) o ensaio foi novamente interrompido e reiniciado sem alteração na direção da deformação. Os resultados mostram que não há alteração no formato da curva de fluxo após interrupções de deformação quando o sentido da deformação não é alterado (cisalhamento a $0^{\circ}$ ). Entretanto, observou-se redução da tensão de fluxo quando o sentido da deformação foi alterado (cisalhamento a $180^{\circ}$ ). 
A Figura 5 mostra curvas de fluxo do alumínio recozido e do alumínio processado por ECAP e cisalhado ao longo do plano xz. Esta direção de cisalhamento está orientada a $45^{\circ}$ do plano de cisalhamento durante o processamento por ECAP, o plano de interseção entre os canais da matriz. Observa-se que a tensão de fluxo do material processado por ECAP é superior à tensão de fluxo do material recozido. Observa-se também que a curva de fluxo do material processado por ECAP apresenta amaciamento a partir de deformações superiores a 0,04 .

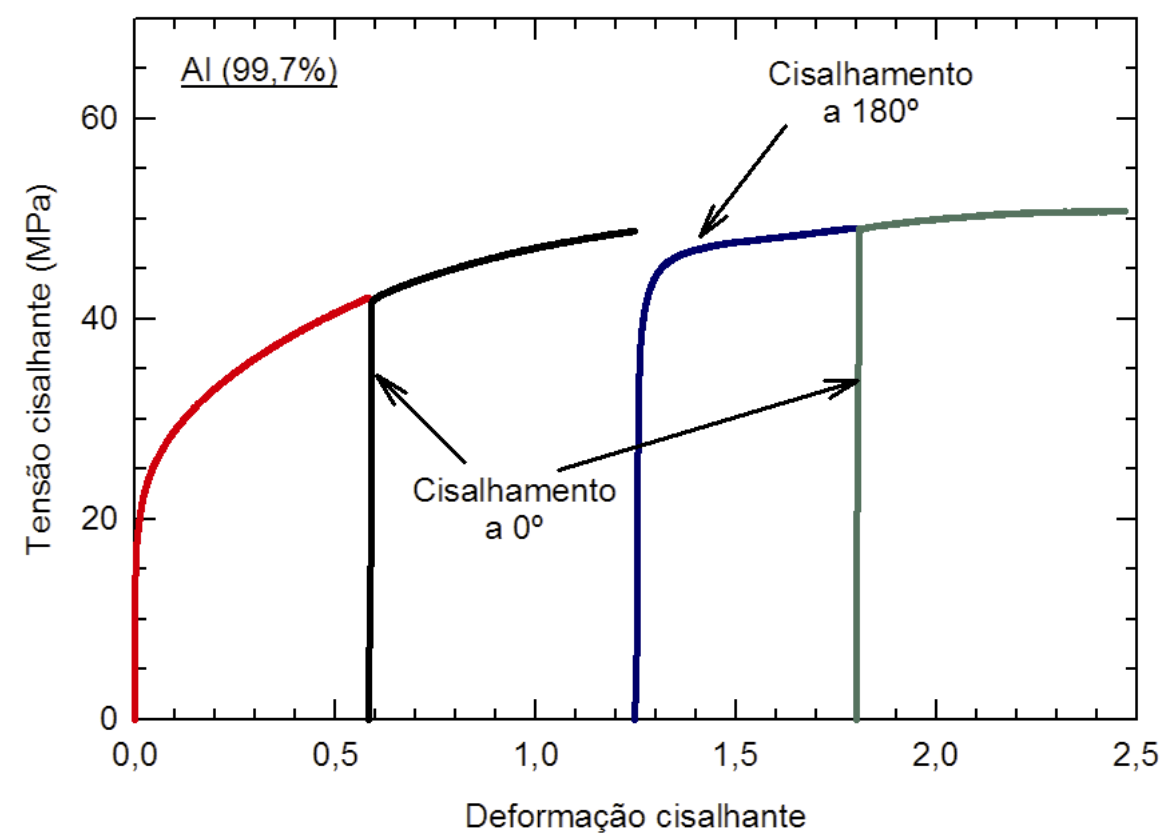

Figura 4. Curva de fluxo do alumínio recozido deformado por cisalhamento com seguidas interrupções da deformação e com alteração do sentido do cisalhamento.

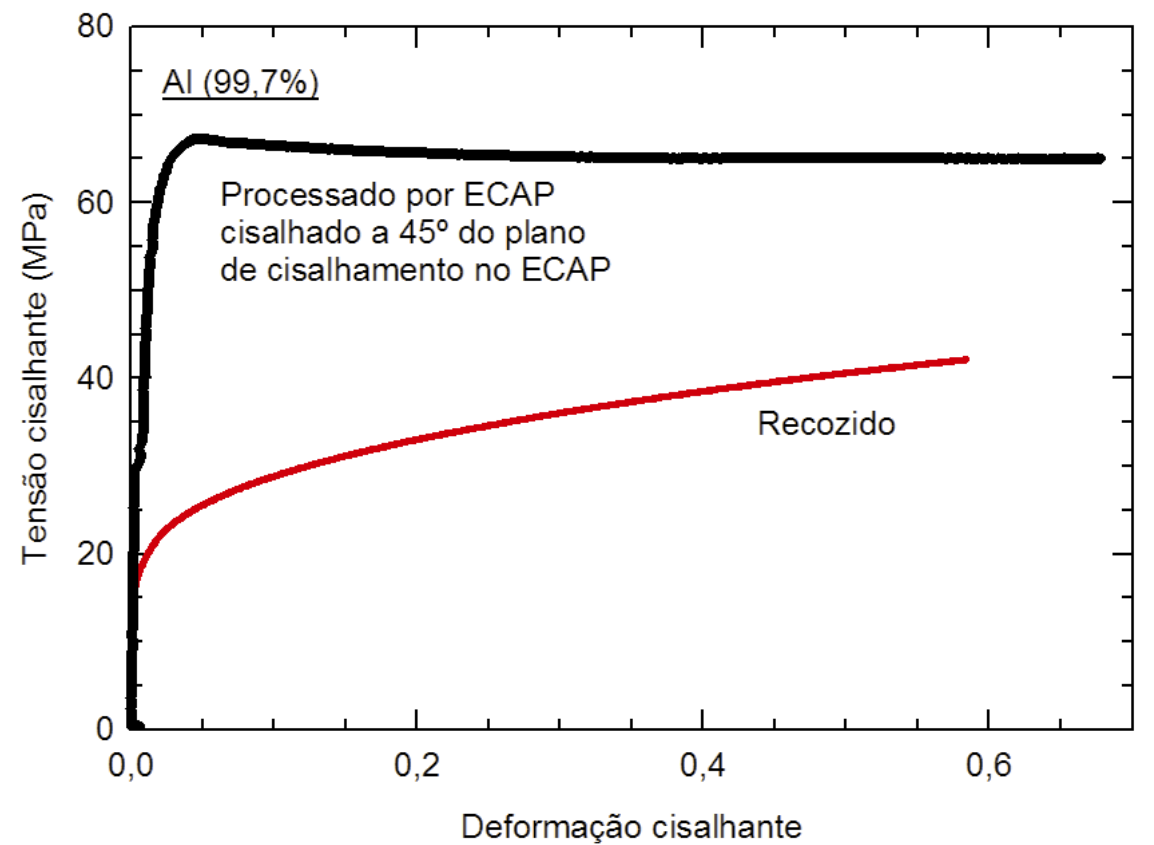

Figura 5. Curvas de fluxo do alumínio recozido e processado por ECAP.

\section{DISCUSSÃO}


Os resultados apresentados anteriormente estão de acordo com as teorias estabelecidas em relação ao efeito da taxa de deformação e do encruamento ${ }^{(1)}$ na evolução da tensão de fluxo do alumínio. Observou-se que o aumento da taxa de deformação promove aumento da tensão de fluxo e o mesmo ocorre com o encruamento. Os resultados também confirmam o "Efeito Baushinger"(1) uma vez que a alteração no sentido da deformação levou a uma redução da tensão de fluxo do material.

A análise da curva de fluxo de materiais com estrutura cúbica de face centrada, c.f.c., pode ser feita através da análise da taxa de encruamento, $d \tau / d \gamma$, plotada em função da tensão cisalhante, $\tau$. Análise similar foi utilizada por Kocks e Mecking. ${ }^{(5)} \mathrm{A}$ figura 6 mostra um gráfico desse tipo calculado a partir dos dados da curva de fluxo do alumínio recozido e cisalhado em diferentes sentidos (Figura 4). Observa-se que a taxa de encruamento segue uma tendência linear nas tensões entre $\sim 30 \mathrm{MPa}$ e $\sim 50 \mathrm{MPa}$. Esta tendência é comum em materiais com estrutura c.f.c. ${ }^{(5)}$ As curvas em vermelho e preto mostram que a tendência é mantida quando o ensaio é interrompido e recomeçado no mesmo sentido. Porém, a inversão do sentido da deformação leva a uma alteração na evolução do encruamento como mostram as curvas preta e azul. A inversão do sentido do cisalhamento leva a um amaciamento reduzindo a tensão em que o material escoa. O material apresenta elevada taxa de encruamento entre $\sim 43 \mathrm{MPa}$ e $\sim 47 \mathrm{MPa}$ e apresenta taxa de encruamento ligeiramente inferior à tendência original entre $\sim 48 \mathrm{MPa}$ e $\sim 49 \mathrm{MPa}$. Após esta variação na taxa de encruamento o material volta a seguir a tendência original até atingir saturação do encruamento a uma tensão de $\sim 50 \mathrm{MPa}$. O formato da curva da taxa de encruamento é semelhante à observada em alumínio submetido a carregamentos reversos. ${ }^{(5)}$ Entretanto, Kocks e Mecking ${ }^{(5)}$ afirmam que o transiente no encruamento do alumínio é afetado em deformações entre $1 \%$ e 3\%. Os resultados atuais mostram que o encruamento só volta à tendência original após uma deformação cisalhante de $\sim 50 \%$, que é a quantidade de deformação imposta no carregamento da curva em azul na Figura 4. O encruamento volta à tendência original na curva em verde.

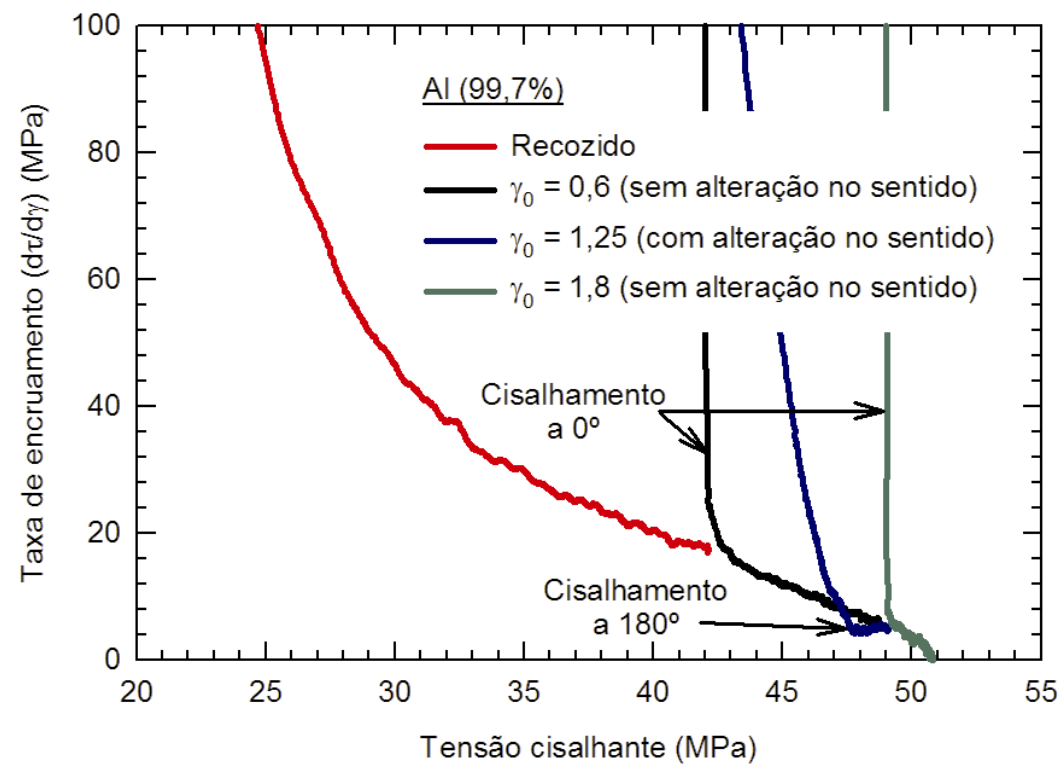

Figura 6. Curvas de taxa de encruamento em função da tensão cisalhante do alumínio submetido a carregamentos em sentidos opostos. 
A curva de fluxo do material processado por ECAP e submetido a cisalhamento também é analisada por meio da taxa de encruamento em função da tensão na Figura 7. É importante notar que a escala da taxa de encruamento foi alterada em relação à figura anterior para mostrar valores negativos uma vez que o material processado por ECAP apresentou amaciamento. A curva da taxa de encruamento do material processado por ECAP é apresentada em valores de tensão superiores ao valor em que o material apresentou saturação quando submetido a carregamento monotônico, $\sim 50 \mathrm{MPa}$. Isto sugere que o encruamento não é o único responsável pelo elevado nível de tensão observado no material processado por ECAP. Além disso, o amaciamento observado no material segue uma tendência linear de variação da taxa de encruamento sugerindo saturação do amaciamento em uma tensão de $\sim 65 \mathrm{MPa}$.

A análise das curvas de fluxo e das taxas de encruamento observadas no alumínio submetido a carregamento monotônico, reverso e carregamento em direções distintas mostra que o caminho de deformação afeta a curva de fluxo e que este efeito pode ser transiente, como no caso do carregamento reverso, ou permanente como no caso do carregamento em direção distinta. Para facilitar a observação desses efeitos a Figura 8 mostra curvas de fluxo com deslocamento em relação ao nível de deformação. A curva de fluxo do alumínio submetido a deformação de 0,55 no sentido reverso é deslocada desta mesma quantidade para valores menores de deformação. Isto está evidenciado na curva verde pontilhada na Figura 8. Observase que esta curva comporta como continuação do carregamento monotônico confirmando que a reversão do sentido de deformação promove um efeito transiente na curva de fluxo e que este efeito é observado por até 0,55 de deformação cisalhante.

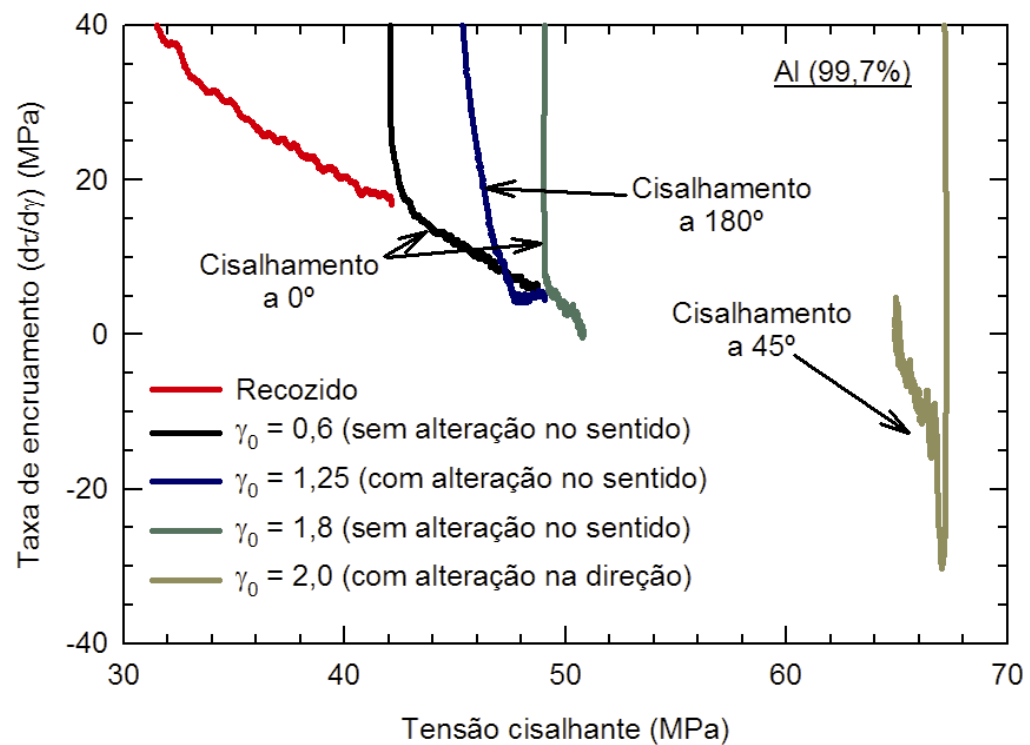

Figura 7. Curvas de taxa de encruamento em função da tensão cisalhante do alumínio submetido a carregamentos em sentidos opostos.

A Figura 8 também mostra a curva de fluxo do material deformado por ECAP deslocada até que sua origem coincida com valores de deformação de 2,0. Esta curva é mostrada em pontilhado marrom. Este nível de deformação cisalhante é o valor imposto durante o ECAP em uma matriz com ângulo entre canais de $90^{\circ} \mathrm{e} \mathrm{sem}$ curvatura externa. ${ }^{(4)}$ Observa-se que a curva do material processado por ECAP satura em um nível de deformação superior ao nível de saturação do cisalhamento 
monotônico confirmando o efeito permanente desta mudança no caminho de deformação.

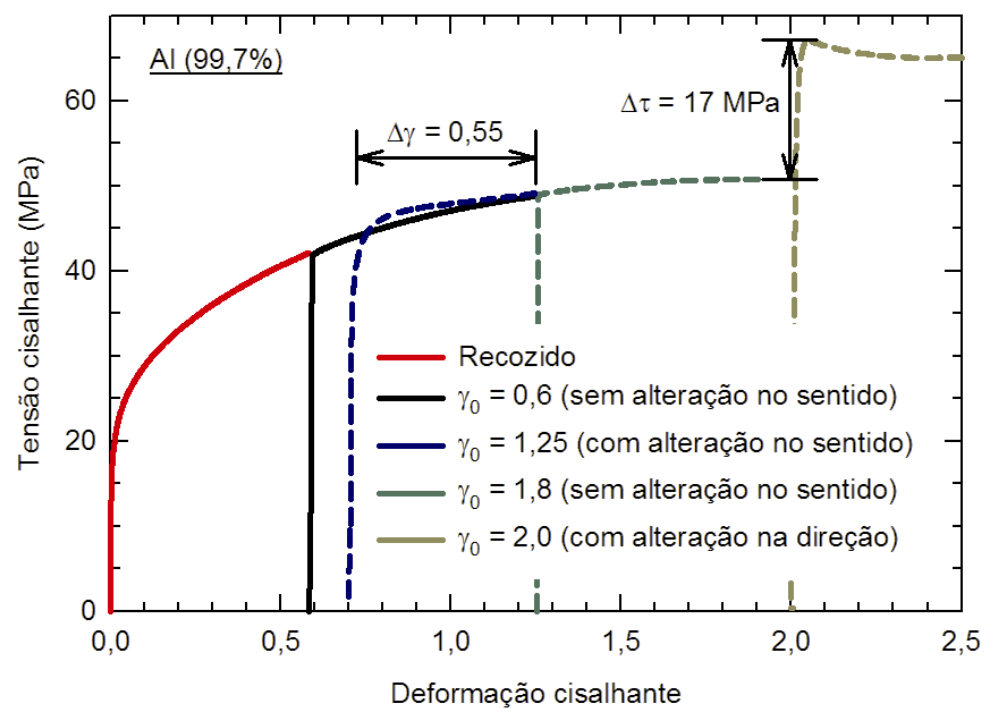

Figura 8. Curvas de fluxo do alumínio submetido a diferentes caminhos de deformação e deslocadas em sua origem.

\section{SUMÁRIO E CONCLUSÕES}

- Alumínio comercialmente puro foi processado por ECAP e submetido a ensaios de cisalhamento. O sentido e a direção da deformação foram variados e as variações na curva de fluxo foram analisadas;

- a reversão do sentido de cisalhamento reduziu o nível da tensão de fluxo e alterou a curva de encruamento de forma transiente. Este transiente corresponde a 0,55 de deformação cisalhante; e

- a alteração na direção do cisalhamento aumentou o nível da tensão de fluxo e alterou a curva de encruamento promovendo o amaciamento do material. A saturação da tensão de fluxo foi alterada permanentemente.

\section{Agradecimentos}

Os autores agradecem o apoio do CNPq, Fapemig e Capes.

\section{REFERÊNCIAS}

1 DIETER G. E. Metalurgia Mecânica. Segunda Edição. Rio de Janeiro, Guanabara koogan, 1981. 653p

2 VALIEV R. Z.; LANGDON T. G. Principles of equal-channel angular pressing as a processing tool for grain refinement. Progress in Materials Science, v. 51, p. 881-981, 2006.

3 ALEXANDER D. J.; BEYERLEIN I. J. Anisotropy in mechanical properties of high-purity copper processed by equal channel angular extrusion. Materials Science and Engineering A, v.410-411, p. 480-4, 2005.

4 IWAHASHI Y.; WANG J.; HORITA Z.; NEMOTO M.; LANGDON T.G. Principle of equalchannel angular pressing for the processing of ultra-fine grained materials. Scripta Materialia, v.35, n. 2, p. 143-6, 1996.

5 KOCKS U. F.; MECKING H. Physics and Phenomenology of strain hardening: the FCC case. Progress in Materials Science v. 48, p. 171-273, 2003 